tinin and disseminated intravascular coagulation. Anesthesiology. 2006; 104:213.

3. Cooper JR, Abrams J, Frazier OH, Radovancevic R, Radovancevic B, Bracey AW, et al. Fatal pulmonary microthrombi during surgical therapy for end-stage heart failure: possible association with antifibrinolytic therapy. J Thorac Cardiovasc Surg. 2006;131:963-8
4. Kottenberg-Assenmacher E, Volbracht L, Jakob H, Greinacher A, Peters J. Disseminated intravascular clotting associated with Fc-receptor IIa-mediated platelet activation in a patient with endocarditis after aortic valve replacement. Br J Anaesth. 2006;97:630-3.

5. Mannucci PM, Levi M. Prevention and treatment of major blood loss. N Engl J Med. 2007;356:2301-11.

\title{
Late perforation of right atrium and aortic root after percutaneous closure of patent foramen ovale
}

Gaetano Palma, MD, Felice Rosapepe, MD, PhD, Mariano Vicchio, MD, Veronica Russolillo, MD, Sabato Cioffi, MD, and Carlo Vosa, MD, Naples, Italy

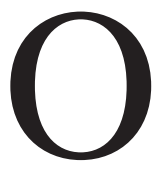

pen heart surgery has been the standard treatment for closure of atrial septal defects (ASDs) for a half century. In the past decade a variety of devices for transcatheter closure of ASDs have become available and an increasing number of patients are treated by this alternative method.

Comparative studies have shown a shorter duration of hospital stay associated with a lower rate of morbidity in patients who underwent percutaneous occlusion than for those treated with classic surgical procedures. ${ }^{1}$ Nevertheless, long-term follow-up has demonstrated excellent outcomes in surgical repair, ${ }^{2}$ although late incidence of device failure and emergency interventions must be analyzed.

We report a case of late perforation of the right atrium and the aortic root by an Amplatzer device (AGA Medical Corp, Golden Valley, Minn) used to close a patent foramen ovale (PFO), necessitating an emergency surgical procedure.

\section{Clinical Summary}

A 28-year-old man with chest pain irradiating to the inferior maxillary bone and interscapular region was brought to the territorial emergency department. Thirteen months earlier, because of a history of cerebral transitory ischemic attacks (TIAs), he had undergone an uncomplicated transcatheter PFO closure with an Amplatzer device at another institution. On clinical examination, the patient was in hemodynamically stable condition, the electrocardiogram showed ST-wave elevation, and the echocardiogram demonstrated an important pericardial effusion without evidence of cardiac tamponade and revealed the right disc of the Amplatzer device leaning toward the aortic root. The transesophageal echocardiogram and computed tomographic scan confirmed that the left atrial disc of the device had perforated the left

From the Department of Cardiothoracic and Respiratory Sciences, Second University of Naples, Naples, Italy.

Received for publication June 7, 2007; accepted for publication June 22, 2007.

Address for reprints: Mariano Vicchio, MD, Via Cassano 150, 80144, Naples, Italy (E-mail: marianovicchio@libero.it).

J Thorac Cardiovasc Surg 2007;134:1054-5

$0022-5223 / \$ 32.00$

Copyright @ 2007 by The American Association for Thoracic Surgery doi:10.1016/j.jtcvs.2007.06.021 atrium and aortic root. The patient was transferred to our institution for the necessary emergency surgical procedure.

The operation was performed through a median sternotomy. Cardiopulmonary bypass was established by ascending aortic and bicaval cannulation. After antegrade cold cardioplegic arrest, we removed the 23-mm Amplatzer device and the adherent wall of the interatrial septum (Figures 1 and 2). A transverse aortotomy was performed to repair the laceration of the aortic root with stitches on pledgets. A Dacron Sauvage patch was used to repair the interatrial septum. The right atrium and the aortotomy were closed directly. The patient had an uncomplicated postoperative recovery and was discharged 6 days later.

\section{Discussion}

Percutaneous transcatheter closure of ASD or PFO has been performed since 1976 as an alternative to conventional surgical repair with various types of mechanical occluder devices. ${ }^{3}$ The Amplatzer septal occluder is a model of such devices and was approved by the Food and Drug Administration in December 2001. A good rate of successful closure has been reported. Nevertheless, cases of late complications necessitating emergency surgical procedures have been described. ${ }^{4}$ Our patient had important anatomic injuries. His hemodynamically stabile condition at the time of surgical repair was a fortunate situation.

Classic open heart surgery remains the standard of care for ASD repair with excellent outcomes since 1954, providing low operative

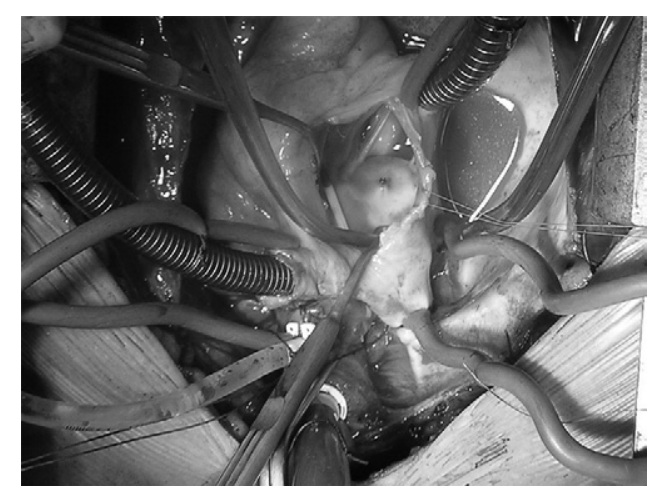

Figure 1. Intraoperative view of the Amplatzer device in the right atrium. 


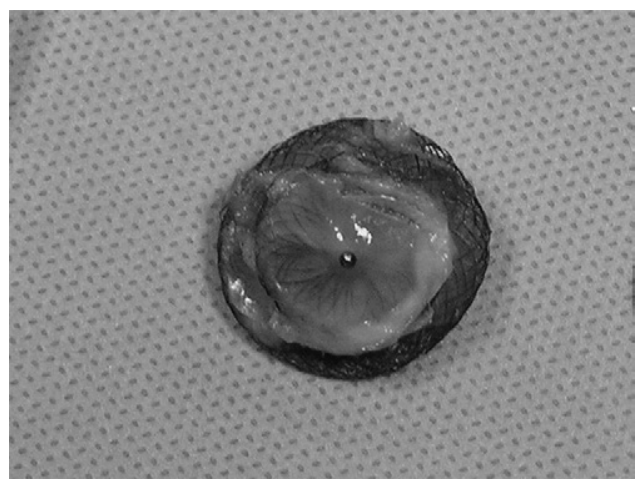

Figure 2. The removed Amplatzer device.

mortality and morbidity. Percutaneous closure is growing rapidly, principally because of the patient's, family's, and pediatric cardiologist's desire for a less invasive procedure. Considering the increase in the number of procedures, a long-term follow-up is necessary to evaluate the safety of mechanical occluders at long term. Our case report described a complication that occurred 13 months after the percutaneous procedure. The literature includes other authors reporting delayed heart perforation by the occluder device ${ }^{5}$, hence this patient's need for long-term echocardiographic follow-up to made an early diagnosis of device failure and prevent emergency surgical intervention. Finally, we conclude that patients should be informed of the actual early and long-term results of surgical repair and percutaneous approach to allow an informed decision.

\section{References}

1. Berger F, Vogel M, Alexi-Meskishvili V, Lange P. Comparison of results and complications of surgical and Amplatzer device closure of atrial septal defects. J Thorac Cardiovasc Surg. 1999;118:674-8.

2. Murphy JG, Gersh BJ, McGoon MD, Mair DD, Porter CJ, Ilstrup DM, et al. Long-term outcome after surgical repair of isolated atrial septal defect. Follow-up at 27 to 32 years. N Engl J Med. 1990 13;323:1645-50.

3. King TD, Mills NL. Secundum atrial septal defect: nonoperative closure during cardiac catheterization. JAMA. 1976;235:2506-9.

4. Contrafouris CA, Chatzis AC, Giannopoulos NM, Milonakis M, Kousi $\mathrm{T}$, Kirvassilis G, et al. Emergency surgical intervention for runaway atrial septal defect closure devices: a word of caution. J Thorac Cardiovasc Surg. 2006;132:1234-5.

5. Teoh K, Wilton E, Brecker S, Jahangiri M. Simultaneous removal of an Amplatzer device from an atrial septal defect and the descending aorta. J Thorac Cardiovasc Surg. 2006;131:909-10.

\section{Complicated acute type B aortic dissection with involvement of an aberrant right subclavian artery and rupture of a thoracoabdominal aortic aneurysm, Crawford type I: Successful emergency endovascular treatment}

Victor X. Mosquera, MD, ${ }^{\text {a }}$ Milagros Marini, MD, $\mathrm{PhD},{ }^{\mathrm{b}}$ Fernando Rodríguez, $\mathrm{MD}{ }^{\mathrm{a}}$ Ignacio Cao, MD, and Alberto Juffé, MD, PhD, ${ }^{\mathrm{a}}$ A Coruña, Spain

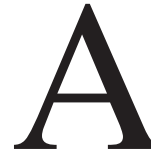

lthough an aberrant right subclavian artery (ARSA) is the most common abnormality of aortic arch development, it is an unusual entity to encounter associated with thoracic aortic dissection. We report the successful endovascular treatment of this association in a critically ill patient.

From the Departments of Cardiothoracic Surgery and Interventional Ra-

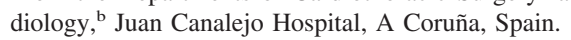

Received for publication June 3, 2007; accepted for publication June 21, 2007.

Address for reprints: Victor X. Mosquera, MD, Cardiac Surgery Department, Hospital Juan Canalejo, As Xubias n ${ }^{\circ} 84$, CP 15006, A Coruña, Spain (E-mail:vxmr@canalejo.org; vxmr@yahoo.es).

J Thorac Cardiovasc Surg 2007;134:1055-7

$0022-5223 / \$ 32.00$

Copyright $\odot 2007$ by The American Association for Thoracic Surgery doi:10.1016/j.jtcvs.2007.06.024

\section{Clinical Summary}

An 80-year-old man was referred to our institution with the diagnosis of an acute aortic Stanford type $\mathrm{B}$ dissection (Figure 1, A). The computed tomographic scan images also showed a thoracoabdominal aortic aneurysm extending from an ARSA (Figure 1, $B$ ) to the esophageal hiatus (Crawford type I).

Because of persistent back pain despite correct intravenous treatment, a new computed tomographic scan was repeated 8 hours later, revealing progression of the aortic dissection and the appearance of a left-sided hemothorax. Blood analysis also showed a fall of 10 points in the hematocrit value.

Because of the patient's critical status and high surgical risk, emergency endovascular treatment was indicated. Notwithstanding, the procedure was technically demanding, because the endograft had to be deployed while avoiding occlusion of the ARSA. However, the diameter of the aortic aneurysm distal to the origin 